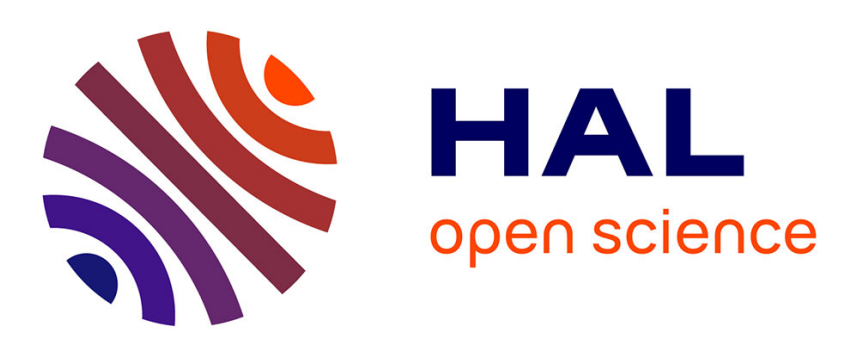

\title{
Dynamic molecular mobility of polyurethane by a broad range dielectric and mechanical analysis
}

David Dupenne, Aurélien Roggero, Eric Dantras, Antoine Lonjon, Thierry

Pierré, Colette Lacabanne

\section{- To cite this version:}

David Dupenne, Aurélien Roggero, Eric Dantras, Antoine Lonjon, Thierry Pierré, et al.. Dynamic molecular mobility of polyurethane by a broad range dielectric and mechanical analysis. Journal of Non-Crystalline Solids, 2017, vol. 468, pp. 46-51. 10.1016/j.jnoncrysol.2017.04.022 . hal-01537201

\section{HAL Id: hal-01537201 \\ https://hal.science/hal-01537201}

Submitted on 12 Jun 2017

HAL is a multi-disciplinary open access archive for the deposit and dissemination of scientific research documents, whether they are published or not. The documents may come from teaching and research institutions in France or abroad, or from public or private research centers.
L'archive ouverte pluridisciplinaire HAL, est destinée au dépôt et à la diffusion de documents scientifiques de niveau recherche, publiés ou non, émanant des établissements d'enseignement et de recherche français ou étrangers, des laboratoires publics ou privés. 


\section{Open Archive TOULOUSE Archive Ouverte (OATAO)}

OATAO is an open access repository that collects the work of Toulouse researchers and makes it freely available over the web where possible.

This is an author-deposited version published in : http://oatao.univ-toulouse.fr/ Eprints ID : 17889

To link to this article : DOI:10.1016/j.jnoncrysol.2017.04.022 URL : http://dx.doi.org/10.1016/j.jnoncrysol.2017.04.022

To cite this version : Dupenne, David and Roggero, Aurélien and Dantras, Eric and Lonjon, Antoine and Pierré, Thierry and Lacabanne, Colette Dynamic molecular mobility of polyurethane by a broad range dielectric and mechanical analysis. (2017) Journal of Non-Crystalline Solids, vol. 468. pp. 46-51. ISSN 0022-3093

Any correspondence concerning this service should be sent to the repository administrator: staff-oatao@listes-diff.inp-toulouse.fr 


\title{
Dynamic molecular mobility of polyurethane by a broad range dielectric and mechanical analysis
}

\author{
D. Dupenne ${ }^{\mathrm{a}, \mathrm{b}}$, A. Roggero ${ }^{\mathrm{b}}$, E. Dantras ${ }^{\mathrm{b}}$, A. Lonjon ${ }^{\mathrm{b}, *}$, T. Pierré $^{\mathrm{a}}$, C. Lacabanne $^{\mathrm{b}}$ \\ a IRT A. de Saint Exupéry, 118 route de Narbonne, 31432 Toulouse Cedex 4, France \\ b CIRIMAT, Université de Toulouse, CNRS, UPS, 118 route de Narbonne, 31062 Toulouse Cedex 09, France
}

\begin{abstract}
A B S T R A C T
The dynamic molecular mobility of poly(2-hydroxypropyl methacrylate) (PHPMA) base polyurethane (PU) was studied over a broad range of frequency and temperature by combining dynamic dielectric spectroscopy and dynamic mechanical analysis. Two hydrated levels were considered in this study: dry and room humidity states. In dry state, two secondary relaxations $\gamma$ and $\beta$ are identified. And in room humidity state, a $\beta$ sw mode is pointed out. These modes are well known in poly(hydroxylalkyl methacrylate)s. The main $\alpha$ relaxation is influenced by humidity and crosslinks. The Kramers-Kronig transform is used to reveal an ionic conductivity $\sigma_{\text {ionic }}$. Relaxation times extracted from dielectric and mechanical analyses are coherent for PU and PHPMA. This correlation allows us to propose an interpretation of relaxations at a molecular level.
\end{abstract}

\section{Introduction}

Poly(hydroxylalkyl methacrylate)s base polyurethane (PU) coatings are widely used in the coating industry $[1,2]$. The PU is classically obtained by the chemical reaction of polyol and isocyanate. A better understanding of relationships between its macromolecular dynamic and structure is necessary to improve these material properties for surface applications.

In previous works, spectroscopic studies have been devoted to the molecular mobility of poly(alkyl methacrylate)s below $\mathrm{Tg}$ [3-19]. Although the mechanical and dielectric behaviors of poly(2-hydroxyethyl methacrylate) (PHEMA) has been extensively studied [20-32], there is a paucity of academic data on the poly(2-hydroxypropyl methacrylate) (PHPMA). PHEMA has a primary alcohol while PHPMA has a secondary alcohol. The reaction with isocyanate is slowed down with a secondary alcohol located on an ester side chain [33]. This increase of reaction time with PHPMA permits to have an acceptable time to apply the coating.

The aim of this work is to study the molecular dynamics of PHPMA by dielectric and mechanical relaxation spectroscopy. The effects of hydration and crosslinking of PHPMA on the relaxation modes are shown and compared with the abundant literature on the water influence on the poly(hydroxylalkyl methacrylate)s relaxations by differential scanning calorimetry [33-40], dynamic dielectric spectroscopy $[26,29,42-44]$ and dynamic mechanical analysis $[45,46]$.

\section{Experimental section}

\subsection{Materials}

The PU coating is a two components system: PHPMA, MACRYNAL ${ }^{\circledR}$ VSM 6299w/42WA (Allnex, Belgium), in $40 \mathrm{wt} \%$ water; and Easaqua ${ }^{\mathrm{TM}}$ X D 401 (Vencorex, France) composed of hexamethylene diisocyanate, isocyanurate (45 wt\%) and 3-isocyanatomethyl-3,5,5-trimethylcyclohexyl isocyanate ( $30 \mathrm{wt} \%)$ in $15 \mathrm{wt} \% n$-butyl acetate. The two parts are mixed at room temperature (ratio 3:1). The mixture is sprayed with a High Volume Low Pressure (HVLP) spray gun. The curing process is $30 \mathrm{~min}$ at $80^{\circ} \mathrm{C}$. In the following sections, PU is referred to as crosslinked PHPMA with a degree of crosslinking of $75 \%$ determined by infrared transmission and PHPMA as the linear base.

\section{Methods}

\subsection{Differential scanning calorimetry}

Differential scanning calorimetry (DSC) experiments were carried out in a DSC 2920 apparatus (TA-Instrument, USA) under nitrogen gas at several heating rates from -60 to $150{ }^{\circ} \mathrm{C}$. The samples weight varied from 5 to $10 \mathrm{mg}$ and they are sealed in aluminum pans. The equivalent frequency $f_{e q, D S C}$ [47] depends on the heating rate following the equation:

\footnotetext{
* Corresponding author.

E-mail address: antoine.lonjon@univ-tlse3.fr (A. Lonjon).
} 
$f_{\text {eq, DSC }}=\frac{v}{2 \pi a \delta T}$

where $v$ is the heating rate, $a$ is a constant $(a \sim 1), \delta T$ is the mean temperature fluctuation.

The associated relaxation time can be determined:

$\tau_{e q, D S C}=\frac{1}{2 \pi f_{e q, D S C}}$

\subsection{Dynamic mechanical analysis}

Dynamic mechanical analysis (DMA) was performed using an ARES G1 strain controlled rheometer (Rheometrics Scientific, USA). Experiments were carried out in rectangular torsion mode, over the temperature range from -145 to $150{ }^{\circ} \mathrm{C}$ at constant angular frequencies, with an heating rate of $3{ }^{\circ} \mathrm{C} / \mathrm{min}$. PU samples were sprayed on silicone mold with $45 \mathrm{~mm}$ length and $10 \mathrm{~mm}$ width. After the curing process, the sample thickness is approximately $500 \mu \mathrm{m}$.

\subsection{Dynamic dielectric spectroscopy}

A dynamic dielectric spectrometer (DDS) BDS 4000 (Novocontrol, Germany) was used in the frequency range from $10^{-2}$ to $10^{+6} \mathrm{~Hz}$ between -150 and $150{ }^{\circ} \mathrm{C}$ by $5{ }^{\circ} \mathrm{C}$ steps. The measurements were carried out in the parallel plates geometry using $35 \mathrm{~mm}$ aluminum circular electrodes. PU coatings were sprayed on the lower electrode. For the second run, the dielectric data were fitted with the HavriliakNegami $[48,49]$ parametric equation, which allowed us to extract the mean dipole relaxation time $\tau_{H N}$ :

$\varepsilon_{\mathrm{T}}^{*}(\omega)=\varepsilon_{\infty}+\frac{\varepsilon_{s}-\varepsilon_{\infty}}{\left[1+\left(i \omega \tau_{H N}\right)^{\alpha H}\right]^{\beta_{H N}}}$

where $\varepsilon_{\infty}$ is the high-frequency limit of the relative real permittivity, $\varepsilon_{s}$ is the low-frequency limit of the relative real permittivity, $\omega$ is the angular frequency and $\alpha_{H N}$ and $\beta_{H N}$ are the Havriliak-Negami fit parameters, respectively related to the width and symmetry of the distribution.

Dipolar relaxations are often hidden by dissipative losses due to ohmic conduction. The Kramers-Kronig [50] relations offer an analytical tool to calculate $\varepsilon_{K K}{ }^{\prime \prime}$ from the real permittivity $\varepsilon_{T}^{\prime}(\omega)$, thus virtually eliminating the contributions of purely dissipative phenomena.

$\varepsilon_{K K}^{\prime \prime}(\omega)=\frac{\sigma_{0}}{\varepsilon_{0} \omega_{0}}+\frac{2}{\pi} \int_{0}^{\infty} \varepsilon_{(\omega)}^{\prime} \frac{\omega_{0}}{\omega^{2}-\omega_{0}^{2}} d \omega$

Molecular mobility is governed by the temperature dependence of $\tau(T)$. Two $\log \tau\left(\frac{1}{T}\right)$ behaviors are classically observed on an Arrhenius plot: a linear and a non-linear one. In the glassy state, the temperature dependence of relaxation times obeys the Arrhenius equation [5]:

$\tau(T)=\tau_{0 a} \exp \left(\frac{\Delta H}{R T}\right)$

where $\tau_{0 a}$ is the pre-exponential factor, $\Delta H$ is the activation enthalpy, $R$ is the gas constant.

For molecular mobility governed by the free volume, the temperature dependency deviates from Arrhenius type behavior; it is then described by the Vogel-Fulcher-Tammann (VFT) equation [51]:

$\tau(T)=\tau_{0 v} \exp \left(\frac{1}{\alpha_{f}\left(T-T_{\infty}\right)}\right)$

where $\tau_{0 v}$ is the pre-exponential factor, $\alpha_{f}$ is the thermal expansion coefficient of the free volume and $T_{\infty}$ is the ideal glass temperature below which there is no free volume.

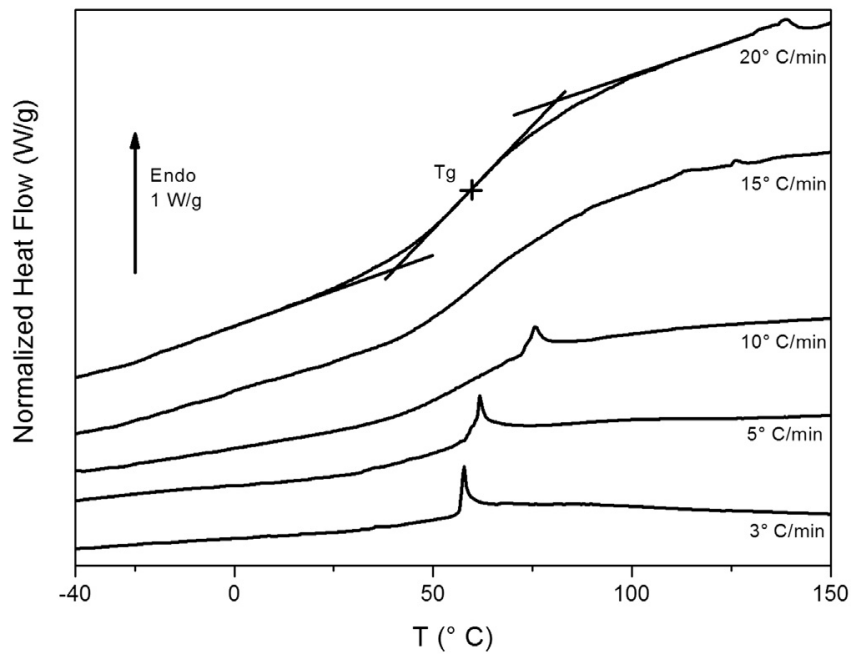

Fig. 1. DSC thermograms of PU for various heating rates (2nd heating). Lines correspond to the inflection point method.

\section{Results and discussions}

\subsection{Physical structure}

DSC analysis of PU was carried out with various heating rates (Fig. 1). The glass transition of PU, determined by the inflection point method (ASTM D3418), remains constant at $60^{\circ} \mathrm{C}$. An endothermic peak is pointed out: its intensity decreases and it is shifted toward higher temperatures with increasing heating rate. This endotherm is associated with the rupture of the hydrogen bonds forming a local order, as in segmented polyurethanes [52].

The extracted temperatures are reported in Table 1.

\subsection{Mechanical relaxations}

The storage modulus $\mathrm{G}^{\prime}$ and the loss modulus $\mathrm{G}^{\prime \prime}$ are reported in Fig. 2 for PU. In order to suppress the influence of water, the second thermograms are shown. The linear behavior of the mechanical response is checked from 1 to $100 \mathrm{rad} / \mathrm{s}$. For the storage modulus $\mathrm{G}^{\prime}$, the glassy plateau is between $1 \mathrm{GPa}$ at $-145^{\circ} \mathrm{C}$ and $0.6 \mathrm{GPa}$ at $20^{\circ} \mathrm{C}$. At high temperature, the rubbery plateau is around $2 \mathrm{MPa}$. Between $30{ }^{\circ} \mathrm{C}$ and $110{ }^{\circ} \mathrm{C}$, the modulus decrease associated with the mechanical manifestation of the glass transition, labelled $\alpha$, is observed. This viscoelastic relaxation is shifted to higher temperatures with increasing angular frequencies.

At lower temperature, two secondary relaxations $\gamma$ and $\beta$ are observed. In order to resolve the lowest temperature mode, the angular frequency is increased toward $100 \mathrm{rad} / \mathrm{s}$. The $\gamma$ peak location is shifted toward higher temperatures as the angular frequency increases. The $\beta$ mode amplitude becomes less intense and tends to merge with the $\alpha$ mode for 50 and $100 \mathrm{rad} / \mathrm{s}$. $T_{\alpha}$ values are consistent with DSC results (Table 1). The relaxation modes temperatures as the function of the angular frequencies are reported in Table 2.

PU are sensitive to hydration, after $48 \mathrm{~h}$ at room humidity ( $\mathrm{RH})$, the

Table 1

. Thermal parameters extracted from of DSC thermograms.

\begin{tabular}{lll}
\hline Heating rate $\left({ }^{\circ} \mathrm{C} / \mathrm{min}\right)$ & $\mathrm{T}_{\mathrm{g}}\left({ }^{\circ} \mathrm{C}\right)$ & $\mathrm{T}_{\text {endo }}\left({ }^{\circ} \mathrm{C}\right)$ \\
\hline 3 & - & $58 \pm 2$ \\
5 & - & $62 \pm 2$ \\
10 & $58 \pm 2$ & $76 \pm 2$ \\
15 & $60 \pm 2$ & $126 \pm 3$ \\
20 & $60 \pm 2$ & $138 \pm 3$ \\
\hline
\end{tabular}




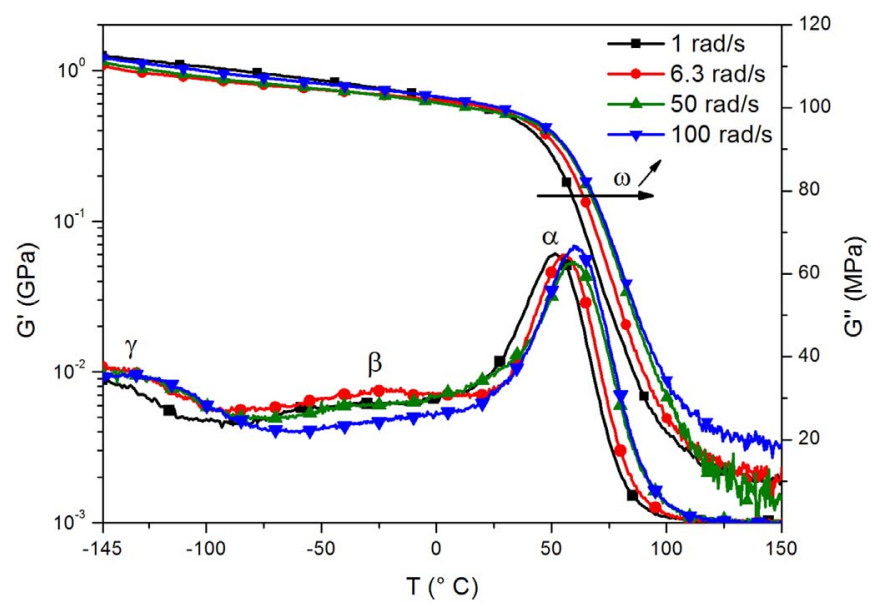

Fig. 2. Storage modulus $G^{\prime}$ and loss modulus $G^{\prime \prime}$ versus temperature for dry PU.

Table 2

Mechanical relaxation modes temperatures for PU at dry and room humidity state.

\begin{tabular}{lllll}
\hline Mode & $T_{1 \mathrm{rad} / \mathrm{s}}{ }^{A M D}\left({ }^{\circ} \mathrm{C}\right)$ & $T_{6.3 \mathrm{rad} / \mathrm{s}}{ }^{A M D}\left({ }^{\circ} \mathrm{C}\right)$ & $T_{50 \mathrm{rad} / \mathrm{s}}{ }^{A M D}\left({ }^{\circ} \mathrm{C}\right)$ & $T_{100 \mathrm{rad} / \mathrm{s}}{ }^{A M D}\left({ }^{\circ} \mathrm{C}\right)$ \\
\hline State & Dry & & & \\
$\gamma$ & - & - & $-140 \pm 2$ & $-135 \pm 2$ \\
$\beta$ & $-30 \pm 2$ & $-25 \pm 2$ & - & - \\
$\alpha$ & $50 \pm 2$ & $55 \pm 2$ & $60 \pm 2$ & $61 \pm 2$ \\
State & $\mathrm{RH}$ & & & \\
$\gamma$ & - & - & $-140 \pm 2$ & $-135 \pm 2$ \\
$\beta$ sw & $-98 \pm 2$ & $-89 \pm 2$ & $-78 \pm 2$ & $-75 \pm 2$ \\
$\beta$ & - & - & - & - \\
$\alpha$ & $47 \pm 2$ & $52 \pm 2$ & $50 \pm 2$ & $52 \pm 2$ \\
\hline
\end{tabular}

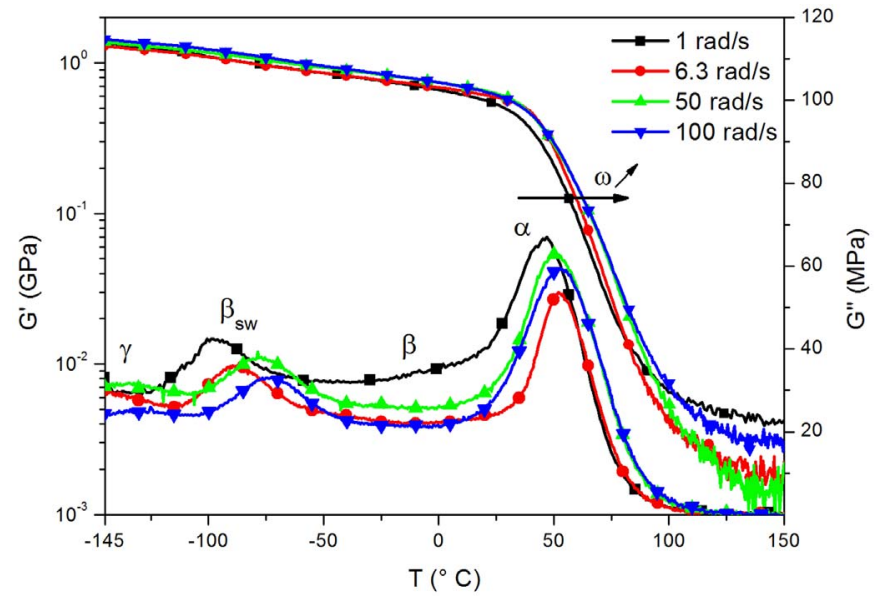

Fig. 3. Storage modulus $\mathrm{G}^{\prime}$ and loss modulus $\mathrm{G}^{\prime \prime}$ versus temperature for PU at RH state.

hydration level is near $1.3 \pm 0.3 \mathrm{wt} \%$. Their dynamic mechanical analyses are reported in Fig. 3.

At RH state, four mechanical relaxation modes are identified $\gamma, \beta s w$, $\beta$ and $\alpha$. Their specific temperatures are reported in the Table 2 as a function of angular frequency. To resolve the lowest temperature mode, the angular frequency is increased toward $100 \mathrm{rad} / \mathrm{s}$. The maximum of $\gamma$ mode is visible above $50 \mathrm{rad} / \mathrm{s}$. The associated temperatures $T_{\gamma}$ are the same for the two hydrated states (dry and $\mathrm{RH}$ ), suggesting that the $\gamma$ mode is not influenced by the presence of humidity.

In the temperature range of -100 to $-75^{\circ} \mathrm{C}$, a new mode, called $\beta s w$, is observed. The index "sw" is defined as "swelling". The molecular origin of this mode is explained later in this article. The $\beta$ mode is hidden by the $\beta$ sw mode and the low temperature tail of $\alpha$ mode. Compared to the dry state, the viscoelastic relaxation mode is

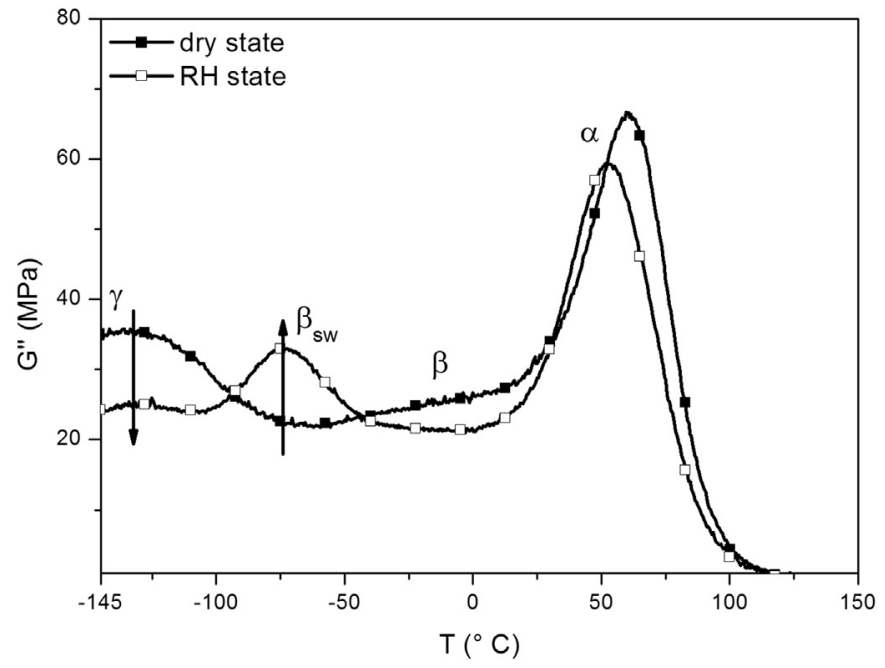

Fig. 4. Modulus loss $\mathrm{G}^{\prime \prime}$ at $100 \mathrm{rad} / \mathrm{s}$ versus temperature for PU in dry and RH states.

shifted toward low temperatures; i.e. characteristic of a plasticization phenomenon.

Fig. 4 compares the dissipative modulus $\mathrm{G}^{\prime \prime}$ for $\mathrm{PU}$ at $100 \mathrm{rad} / \mathrm{s}$ for dry and RH states. $\gamma$ mode strength decreases strongly in the RH state, contrary to $\beta$ sw mode. The presence of humidity changes the amplitude of $\gamma$ mode, but its temperature is unchanged.

\subsection{Dielectric relaxations}

Fig. 5 reports the dielectric loss surface of PU at RH state. Dielectric relaxation modes are consistent with mechanical results. In addition an ionic conductivity $\sigma_{\text {ionic }}$ is observed at high temperatures and low frequencies. This dielectric contribution appears in the high frequency tail of the conductivity $\sigma$. This phenomenon has been associated with ions accumulation at electrode-sample interfaces, leading to a so-called "electrode polarization" effect [53] superimposed to the high-temperature conductivity in Fig. 5.

The dynamic conductivity $\sigma^{\prime}$ and permittivity $\varepsilon^{\prime}$ at $150{ }^{\circ} \mathrm{C}$ are reported in Fig. 6. For high frequency range, the conductivity is frequency dependent. It corresponds to ion mobility at short times $[54,55]$. At lower frequency, a nearly constant $\left(\sigma_{\mathrm{dc}}\right)$ plateau, associated with random ions hopping mobility, is observed. With decreasing frequency, the accumulation of ions near the electrodes leads to a

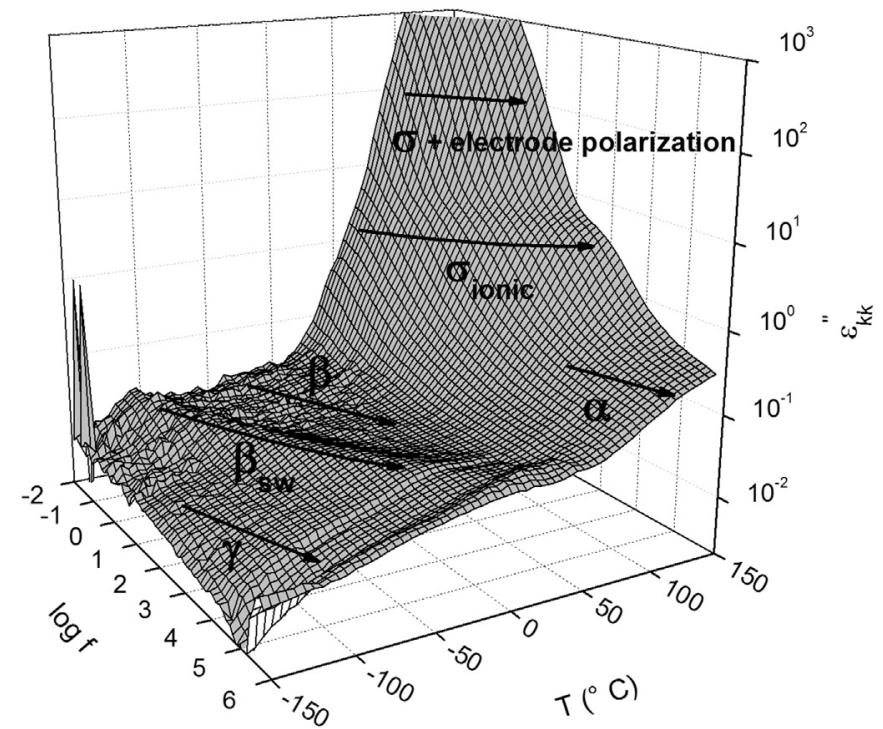

Fig. 5. Dielectric loss $\varepsilon^{\prime \prime}$ surface for PU at RH state. 


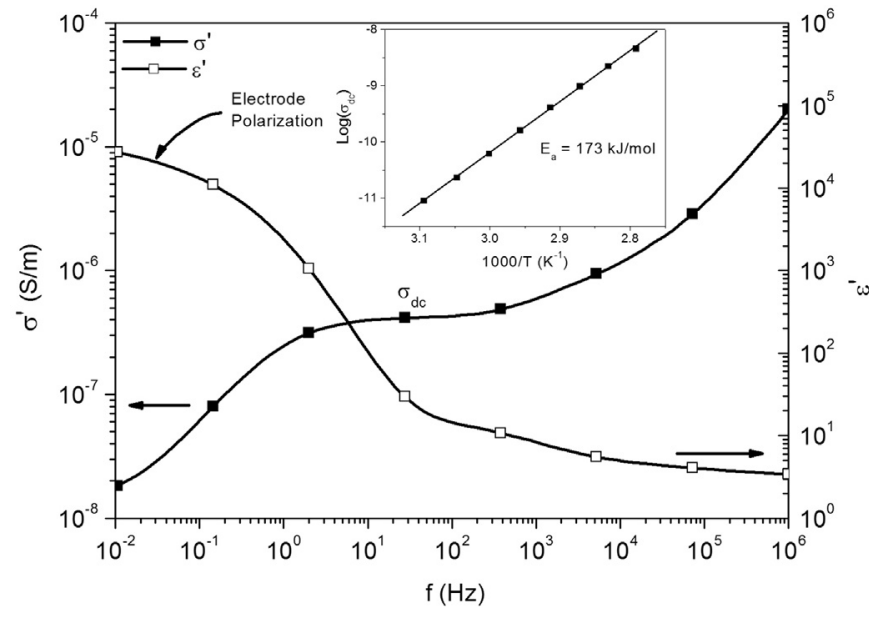

Fig. 6. Real part of the conductivity $\sigma^{\prime}$ and permittivity $\varepsilon^{\prime}$ versus frequency for PU at $150^{\circ} \mathrm{C}$. Inset: Arrhenius diagram of $\log \sigma_{D C}$.

decrease in the mobile ions density within the sample ( $\sigma^{\prime}$ decreases). And additional polarization of the sample is induced by the ions stacked near the electrodes, resulting in an increase of $\varepsilon^{\prime}$ [53]. The inset in Fig. 6 shows that ionic conductivity is governed by an Arrhenius behavior with an activation energy greater than $100 \mathrm{~kJ} / \mathrm{mol}$. It confirms an ionic charge transport.

Fig. 7 shows the relaxation times behaviors on an Arrhenius diagram for PU in the dry and RH states. DDS and DMA relaxation times are reported. The temperature dependence of the $\gamma, \beta$ sw, $\beta, \alpha$ relaxations and $\sigma_{\text {ionic }}$ are shown. Secondary relaxations and $\sigma_{\text {ionic }}$ follow the Arrhenius behavior law described by Eq. (5). The extracted parameters are indexed in Table 3.

For the $\gamma$ mode, we observe a discrepancy between dielectric and mechanical relaxation times at low temperature. It has been already reported in the literature $[20,22,32,56]$. The dielectric response under electric field is strongly dependent on the dipole moment, whereas the mechanical relaxation is directly linked with molecular mobility and Van der Waals binding forces. Aligning the dipole moment of $-\mathrm{OH}$ group in the electric field is easier than overcoming the Van der Waals interactions.

At RH conditions, the $\beta$ mode cannot be fitted due to $\beta$ sw relaxation. Mechanical and dielectric relaxation times are in agreement for $\beta s w$ and $\beta$ modes, contrary to Gates et al. [22] results. They observe a $\beta$ sw

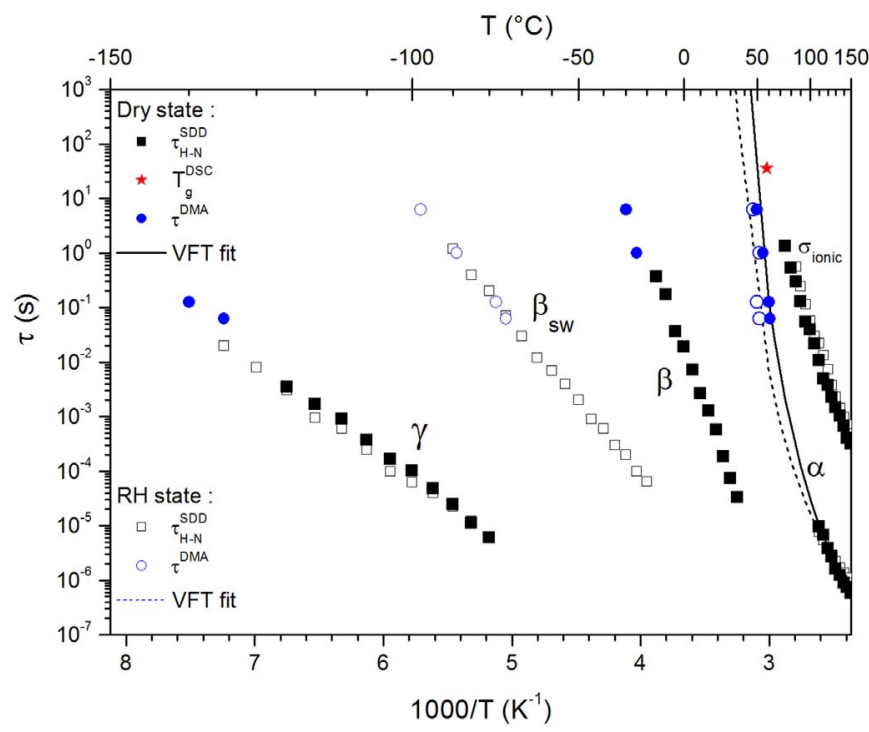

Fig. 7. Arrhenius diagram of dielectric and mechanical relaxations times of PU at dry and RH states. Lines correspond to VFT fit.
Table 3

Arrhenius fit parameters for secondary relaxations and $\sigma_{\text {ionic }}$ in $\mathrm{PU}$ at dry and $\mathrm{RH}$ states.

\begin{tabular}{llllll}
\hline State & \multicolumn{3}{l}{ Dry } & & \multicolumn{2}{l}{$\mathrm{RH}$} \\
\cline { 2 - 3 } \cline { 5 - 6 } Mode & $\tau_{0}(\mathrm{~s})$ & $\mathrm{E}_{\mathrm{a}}(\mathrm{kJ} / \mathrm{mol})$ & & $\tau_{0}(\mathrm{~s})$ & $\mathrm{E}_{\mathrm{a}}(\mathrm{kJ} / \mathrm{mol})$ \\
\hline$\gamma$ & $5.10^{-15}$ & $34 \pm 1$ & & $1.10^{-14}$ & $32 \pm 1$ \\
$\beta$ Bsw & - & - & & $5.10^{-16}$ & $54 \pm 1$ \\
$\beta$ & $6.10^{-26}$ & $123 \pm 2$ & & - & - \\
$\sigma_{\text {ionic }}$ & $4.10^{-21}$ & $136 \pm 3$ & & $4.10^{-21}$ & $136 \pm 2$ \\
\hline
\end{tabular}

Table 4

VFT fit parameters of $\alpha$ relaxation in PU at dry and RH states.

\begin{tabular}{lllll}
\hline Mode & State & $\tau_{0}(\mathrm{~s})$ & $T_{\infty}\left({ }^{\circ} \mathrm{C}\right)$ & $\alpha_{\mathrm{f}}\left({ }^{\circ} \mathrm{C}^{-1}\right)$ \\
\hline$\alpha$ & Dry & $2.10^{-10}$ & $2 \pm 1$ & $8.10^{-4}$ \\
& RH & $3.10^{-9}$ & $1 \pm 1$ & $1.10^{-3}$ \\
\hline
\end{tabular}

peak slightly lower for dielectric measurements. The $\gamma$ relaxation and $\sigma_{\text {ionic }}$ dielectric contributions are not influenced by hydration. $\alpha$ mode is governed by a VFT behavior. A plasticization phenomenon due to water molecules is observed. VFT fit parameters are reported in Table 4. The ideal glass temperature $T_{\infty}$ is located at $56{ }^{\circ} \mathrm{C}$ below the calorimetric $\mathrm{Tg}$ in the dry state.

Eq. (2) allows us to calculate the equivalent relaxation time $\tau_{e q, D S C}$, approximately $30 \mathrm{~s}$, for a heating rate of $20^{\circ} \mathrm{C} / \mathrm{min}$ and reported in Fig. 7. The calorimetric $\mathrm{Tg}$ is consistent with the mechanical and dielectric measurements.

In order to shed some light on the molecular origin of these relaxation dynamics and to study the effect of crosslinking, the dielectric permittivity of PHPMA in the dry and RH states was studied. Due to the weak mechanical properties of PHPMA, DMA analyses could not performed.

In Fig. 8, relaxation times temperature dependence of PHPMA are reported on an Arrhenius diagram. In the glassy state, the secondary relaxations are governed by the Arrhenius law and the fitted parameters are reported in Table 5. These $\gamma$, $\beta$ sw, $\beta$ modes of PHPMA are consistent with those observed in PU.

The $\gamma$ relaxation process is associated with the rotation of the $-\mathrm{OH}$ side groups as in PHEMA [32]. In the $\mathrm{PU}$, all the $-\mathrm{OH}$ functions do not react with the $-\mathrm{NCO}$ functions to form the PU function. The $\gamma$ mode remains relatively constant with water molecule presence, as a con-

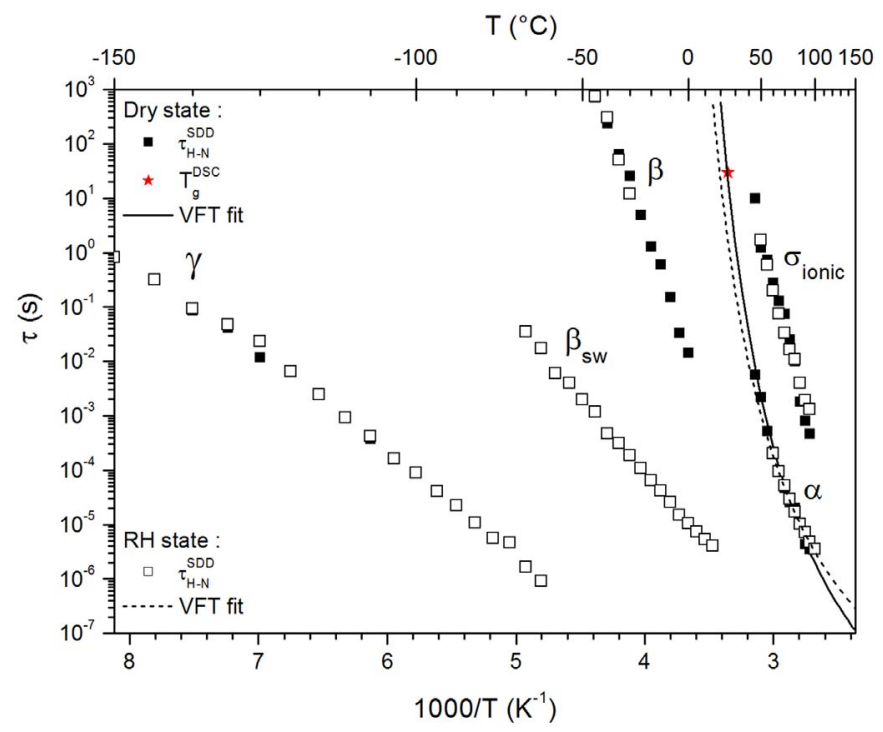

Fig. 8. Arrhenius diagram of relaxation times of PHPMA at dry and RH states. Lines correspond to VFT fit. 
Table 5

Arrhenius fit parameters for the secondary relaxations and $\sigma_{\text {ionic }}$ in PHPMA at dry and RH states.

\begin{tabular}{|c|c|c|c|c|}
\hline \multirow{2}{*}{$\begin{array}{l}\text { State } \\
\text { Mode }\end{array}$} & \multicolumn{2}{|l|}{ Dry } & \multicolumn{2}{|l|}{ RH } \\
\hline & $\tau_{0}(\mathrm{~s})$ & $\mathrm{E}_{\mathrm{a}}(\mathrm{kJ} / \mathrm{mol})$ & $\tau_{0}(\mathrm{~s})$ & $\mathrm{E}_{\mathrm{a}}(\mathrm{kJ} / \mathrm{mol})$ \\
\hline$\gamma$ & $7.10^{-15}$ & $34 \pm 1$ & $2.10^{-15}$ & $35 \pm 1$ \\
\hline$\beta$ sw & - & - & $1.10^{-15}$ & $52 \pm 1$ \\
\hline$\beta$ & $9.10^{-27}$ & $127 \pm 2$ & $1.10^{-27}$ & $131 \pm 2$ \\
\hline$\sigma_{\text {ionic }}$ & $1.10^{-30}$ & $187 \pm 2$ & $1.10^{-30}$ & $188 \pm 2$ \\
\hline
\end{tabular}

Table 6

VFT fit parameters of the $\alpha$ relaxation in PHPMA at dry and RH states.

\begin{tabular}{lllll}
\hline Mode & State & $\tau_{0}(\mathrm{~s})$ & $T_{\infty}\left({ }^{\circ} \mathrm{C}\right)$ & $\alpha_{\mathrm{f}}\left({ }^{\circ} \mathrm{C}^{-1}\right)$ \\
\hline \multirow{2}{*}{$\alpha$} & Dry & $1.10^{-10}$ & $-20 \pm 2$ & $8.5 .10^{-4}$ \\
& RH & $8.10^{-10}$ & $-22 \pm 1$ & $1.10^{-3}$ \\
\hline
\end{tabular}

firmation of Janacek [20] interpretation on PHEMA swollen (with different concentrations of water or other polar solvents) by mechanical experiments. Janacek et al. show that its $\gamma$ mode gradually disappears with increasing diluent concentration but its temperature location is constant. Gates et al. [22] mention that the activation energy of the $\gamma$ mode is constant for cross-linked HEMA, DHPMA and their copolymers, and not dependent from hydration. But Lustig et al. [57] observed for PHEMA a slight decrease toward lower temperatures with water content, while Shen et al. [58] for PHEMA and PHPMA noted the opposite. In this work, the activation energy value for the $\gamma$ relaxation is about $34 \mathrm{~kJ} / \mathrm{mol}$. This result is in agreement with the ones previously established for polyacrylic systems with hydroxyl groups as PHEMA $[22,32,59,60]$ or PHEA [61].

In $\mathrm{RH}$ state, the $\beta$ sw mode is also observed. Literature reports that it is shifted toward lower temperatures as water content increases for the PHEMA [62] and for the PHEA [19]. This mode has been associated with water molecules in interaction with hydroxypropyl group on the polymer side chain [20]; i.e. a complex - OH side groups/water. A part of $-\mathrm{OH}$ side groups involve in the $\gamma$ process is transformed into the $\beta \mathrm{sw}$ process. The activation energy is $52 \mathrm{~kJ} / \mathrm{mol}$ which is consistent with the values from literature $[60,61]$.

As already observed in DMA, the $\beta$ mode is hidden by the $\beta$ sw relaxation. Only a few points can be fitted with the HN function in the RH state. The secondary mode $\beta$ corresponds to the rotation of the ester side group [20]. The activation energies in the dry and hydrated state are close. In the literature, the temperature of the $\beta$ mode slightly decreases with water content $[57,58]$. The activation energy values obtained for the $\beta$ mode are similar to those reported for PHEMA $[59,24]$.

At higher temperatures, the $\sigma_{\text {ionic }}$ obeys an Arrhenius behavior and is not influenced by hydration. The activation energy of the secondary modes between PHPMA and PU are close. There is no influence on these modes when PHPMA is crosslinked. Only, the ionic conductivity $\sigma_{\text {ionic }}$ is modified. The activation energy is higher in the PHPMA.

A VFT behavior is observed for the PHPMA $\alpha$ mode. The VFT fit parameters are reported in Table 6 . The ideal glass transition temperature $T_{\infty}$, located in the vicinity of $-20{ }^{\circ} \mathrm{C}$, is $45^{\circ} \mathrm{C}$ below the calorimetric $\mathrm{Tg}$ in the dry state $\left(\mathrm{T}_{\mathrm{g}}(P H P M A)=25^{\circ} \mathrm{C}\right)$. In the same way as $\mathrm{PU}$, the point $\left(\mathrm{T}_{\mathrm{g}}(P H P M A), \tau_{e q, D S C}\right)$ has been reported in Fig. 8, and is in good agreement with VFT fit. The $\alpha$ relaxation for the PU is shifted to higher temperatures as compared to the PHPMA by crosslinking limiting the degrees of freedom of the main chain segments involved in the glass transition.

\section{Conclusions}

Mechanical and dielectric relaxations have been applied to thorough investigation of the dynamic molecular mobility of PHPMA and PU in dry and RH states. The combination of DMA and DDS has brought to light the correlation between the response of this mobility under mechanical and electric field.

At low temperature in the dry state, two secondary relaxation modes $\gamma$ and $\beta$ were identified in PHPMA and PU. The molecular origin of the $\gamma$ mode is the rotation of the $-\mathrm{OH}$ side group in PHPMA. The $\beta$ secondary relaxation mode is attributed to the rotation of the ester side group. Their relaxation times are not modified by humidity and crosslinking. For RH conditions, the $\beta$ sw mode has been observed and associated with water molecules in interaction with $-\mathrm{OH}$. This mode isn't modified by crosslinking. At high temperature in the dry state, the $\alpha$ relaxation of PHPMA is shifted to higher temperatures in PU due to crosslinking.

Once hydrated, a plasticization phenomenon appears for PHPMA and PU. In dielectric analysis, an ionic conductivity $\sigma_{\text {ionic }}$ is associated with ions accumulation at electrodes. This phenomenon is not influenced by humidity but by crosslinking. Finally, the good consistency between DMA and DDS results allows us to significantly improve the knowledge of molecular/dynamic structure relationships of PHPMA base PU coating.

\section{Acknowledgments}

These results were obtained under the research project "SURFINNOV" at the IRT Saint Exupéry. We thank the industrial and academic members of the IRT who supported this project through their contributions, both financial and in terms of specific knowledge:

- Industrial members: Airbus Defence \& Space, Airbus Group Innovation, Airbus Helicopter, Airbus Operation, Akzo, GIT, Liebherr, Mapaero, Mecaprotec, Prodem, Socomore, Stelia Aerospace, Thales Alenia Space

- Academic members: CIRIMAT, Laplace, UPS and CNRS.

We also thank the "Commissariat Général aux Investissements" and the "Agence Nationale de la Recherche" for their financial support in the "Programme d'Investissement d'Avenir" (PIA).

\section{References}

[1] P.S. Suchithra, V.K. Abitha, D. Patil, A.V. Rane, Effect of hydroxyl value of acrylic polyol and type of crosslinkers on the properties of polyurethane coatings, Moroccan J. Chem. 3 (2015) 476-483.

[2] D.J. Mills, S.S. Jamali, K. Paprocka, Investigation into the effect of nano-silica on the protective properties of polyurethane coatings, Surf. Coat. Technol. 209 (2012) $137-142$.

[3] F. Garwe, A. Schönhals, H. Lockwenz, M. Beiner, K. Schröter, E. Donth, Influence of cooperative $\alpha$ dynamics on local $\beta$ relaxation during the development of the dynamic glass transition in poly(n-alkyl methacrylate)s, Macromolecules 29 (1996) $247-253$.

[4] M.A. Desando, M.A. Kashem, M.A. Siddiqui, S. Walker, Dielectric studies of the $\beta 1$ and $\beta 2$ processes of poly(alkyl methacrylate) polymers, J. Chem. Soc., Faraday Trans. 280 (1984) 747-762.

[5] N.G. McCrum, B.E. Read, G. Williams, Anelastic and Dielectric Effects in Polymeric Solids, John Wiley, 1967.

[6] J. Janacek, J. Kolarik, Relaxation behavior of poly(methacrylic acid) esters swollen by low molecular weight substances at temperatures below the glass transition point, J. Polym. Sci. C 16 (1967) 279-291.

[7] F. Lednicky, J. Janacek, Relaxation behavior of the ester groups ( $\beta$ dispersion) in some swollen polymethacrylates, J. Macromol. Sci. Part B. 5 (1971) 335-354.

[8] T.W. Wilson, D.T. Turner, Vitrification of water in a hydrogel, Macromolecules 21 (1988) 1184-1186.

[9] K. Mpoukouvalas, G. Floudas, G. Williams, Origin of the $\alpha, \beta,(\beta \alpha)$, and "Slow" dielectric processes in poly(ethyl methacrylate), Macromolecules 42 (2009) 4690-4700.

[10] H. Sasabe, S. Saito, Dielectric relaxations and electrical conductivities of poly(alkyl methacrylates) under high pressure, J. Polym. Sci. Part A-2 (6) (1968) 1401-1418.

[11] K. Schröter, R. Unger, S. Reissig, F. Garwe, S. Kahle, M. Beiner, E. Donth, Dielectric spectroscopy in the $\alpha \beta$ splitting region of glass transition in poly(ethyl methacry- 
late) and poly(n-butyl methacrylate): different evaluation methods and experimental conditions, Macrolecules. 31 (1998) 8966-8972.

[12] G. Floudas, Structure and dynamics of poly(n-decyl methacrylate) below and above the glass transition, Macromolecules 31 (1998) 6951-6957.

[13] M. Beiner, K. Schröter, E. Hempel, S. Reissig, E. Donth, Multiple glass transition and nanophase separation in poly(n-alkyl methacrylate) homopolymers, Macromolecules 32 (1999) 6278-6282.

[14] E. Dudognon, A. Berne, C. Lacabanne, Study by thermostimulated currents of dielectric relaxations through the glass transition in an amorphous polymer: poly(nbutyl methacrylate), Macromolecules 34 (2001) 3988-3992.

[15] E. Dudognon, A. Berne, C. Lacabanne, Low-frequency chain dynamics of poly(nhexyl methacrylate) by dielectric spectroscopies, Macromolecules 35 (2002) 5927-5931.

[16] E. Dudognon, A. Bernès, C. Lacabanne, Nature of molecular mobility through the glass transition in poly(n-alkyl methacrylates): a study by dielectric spectroscopies, J. Macromol. Sci. Part B. 43 (2004) 591-604.

[17] C. Menissez, B. Sixou, L. David, G. Vigier, Dielectric and mechanical relaxation behavior in poly(butyl methacrylate) isomers, J. Non-Cryst. Solids 351 (2005) 595-603.

[18] A. Kyritsis, P. Pissis, J.L. Gomez Ribelles, M. Pradas, Dielectric relaxation spectroscopy in PHEA hydrogels, J. Non-Cryst. Solids 172-174 (1994) 1041-1046.

[19] A. Kyritsis, P. Pissis, J. Ribelles, M. Pradas, Polymer-water interactions in poly (hydroxyethyl acrylate) hydrogels studied by dielectric, calorimetric and sorption isotherm measurements, Polym. Gels Networks 3 (1995) 445-469.

[20] J. Janacek, Mechanical behavior of hydroxyalkyl methacrylate polymers and copolymers, J. Macromol. Sci. Part C Polym. Rev. 9 (1973) 3-47.

[21] J. Kolarik, Secondary relaxations in glassy polymers: hydrophilic polymethacrylates and polyacrylates, J. Adv. Polym. Sci. 46 (1982) 119-161.

[22] G. Gates, J. Harmon, J. Ors, P. Benz, Intra and intermolecular relaxations 2,3dihydroxypropyl methacrylate and 2-hydroxyethyl methacrylate hydrogels, Polymer (Guildf). 44 (2003) 207-214.

[23] R. Diaz Calleja, Dielectric $\gamma$ relaxation in poly (2-hydroxyethyl methacrylate), J. Polym. Sci. Part B Polym. Phys. 17 (1979) 1395-1401.

[24] J.L. Gomez Ribelles, R. Diaz Calleja, The $\beta$ dielectric relaxation in some methacrylate polymers, J. Polym. Sci. Part B Polym. Phys. 23 (1985) 1297-1307.

[25] G.A. Russell, P. Hiltner, D. Gregonis, A. DeVisser, J. Andrade, Thermal and dynamic mechanical relaxation behavior of stereoregular poly(2-hydroxyethyl methacrylate), J. Polym. Sci. B Polym. Phys. 18 (1980) 1271-1283.

[26] K. Pathmanathan, G.P. Johari, Dielectric and conductivity relaxations in poly (hema) and of water in its hydrogel, J. Polym. Sci. Part B Polym. Phys. 28 (1990) 675-689.

[27] G.P. Johari, Dielectric behaviour of H-bonded liquids and amorphous and crystalline solids, J. Mol. Struct. 250 (1991) 351-384.

[28] A. Kyritsis, P. Pissis, J.L.G. Ribelles, M.M. Pradas, Depolarization thermocurrent studies in poly(hydroxyethyl acrylate)/water hydrogels, J. Polym. Sci. Part B Polym. Phys. 32 (1994) 1001-1008.

[29] K. Pathmanathan, G.P. Johari, Relaxation and crystallization of water in a hydrogel, J. Chem. Soc. Faraday Trans. 90 (1994) 1143-1148.

[30] N. Araujo, D. Gomes, J.L.G. Ribelles, M.M. Pradas, J.F. Mano, Dynamic-mechanical behavior of hydrophobic-hydrophilic interpenetrating copolymer networks, Polym. Eng. Sci. 46 (2006) 930-937.

[31] M. Salmeron Sanchez, R. Brigido Diego, S.A.M. Iannazzo, J.L. Gomez Ribelles, M. Pradas, The structure of poly(ethyl acrylate-co-hydroxyethyl methacrylate) copolymer networks by segmental dynamics studies based on structural relaxation experiments, Polymer (Guildf). 45 (2004) 2349-2355.

[32] K. Mohomed, T.G. Gerasimov, F. Moussy, J.P. Harmon, A broad spectrum analysis of the dielectric properties of poly(2-hydroxyethyl methacrylate), Polymer (Guildf). 46 (2005) 3847-3855.

[33] Z.W. Wicks, D.A. Wicks, J.W. Rosthauser, Two package waterborne urethane systems, Prog. Org. Coat. 44 (2002) 161-183.

[34] P.H. Corkhill, A.M. Jolly, C.O. Ng, B.J. Tighe, Synthetic hydrogels: 1. Hydroxyalkyl acrylate and methacrylate copolymers - water binding studies, Polymer (Guildf). 28 (1987) 1758-1766.

[35] K. Hofer, E. Mayer, Glass-liquid transition of water and ethylene glycol solution in poly(2-hydroxyethyl methacrylate) hydrogel, J. Phys. Chem. 94 (1990) 2689-2696.

[36] B. Ramaraj, G. Radhakrishnan, Modification of the dynamic swelling behaviour of poly(2-hydroxyethyl methacrylate) hydrogels in water through interpenetrating polymer networks (IPNs), Polymer (Guildf). 35 (1994) 2167-2173.

[37] M.B. Ahmad, M.B. Huglin, States of water in poly(methyl methacrylate-co-N-vinyl2-pyrrolidone) hydrogels during swelling, Polymer (Guildf). 35 (1997) 1997-2000.

[38] G. Smyth, F.X. Quinn, V.J. McBrierty, Water in hydrogels. 2. A study of water in poly(hydroxyethyl methacrylate), Macromolecules 21 (1988) 3198-3204.

[39] J. Rault, A. Lucas, R. Neffati, M. Monleo, Thermal transitions in hydrogels of poly (ethyl acrylate)/poly(hydroxyethyl acrylate) interpenetrating networks, Macromolecules 30 (1997) 7866-7873.

[40] F.X. Quinn, E. Kampff, G. Smyth, V.J. Mcbrierty, Water in hydrogels. 1. A study of water in poly(N-vinyl-2-pyrrolidone/methyl methacrylate) copolymer, Macromolecules 21 (1988) 3191-3198.

[42] J.L. Gomez Ribelles, J.M. Meseguer Duenas, M. Pradas, Dielectric relaxations in poly(hydroxyethyl acrylate): influence of the absorbed water, Polymer (Guildf). 29 (1988) 1124-1127.

[43] M.B.I.N. Ahmad, J.P.O. Mahony, M. Huglin, T.P. Davis, A.C. Rlcclardone, Application of dielectric spectroscopy and DSC to the study of relaxations in some copolymeric hydrogels, J. Appl. Polym. Sci. 56 (1995) 397-404.

[44] H. Xu, J.K. Vij, V.J. McBrierty, Wide-band dielectric spectroscopy of hydrated poly (hydroxyethyl methacrylate), Polymer (Guildf). 35 (1994) 227-234.

[45] L.M. Muratore, K. Steinhoff, T.P. Davis, Self-reinforcing hydrogels comprised of hydrophobic methyl methacrylate macromers copolymerised with either N-vinyl-2pyrrolidone or 2-hydroxyethyl acrylate, J. Mater. Chem. 9 (1999) 1687-1691.

[46] G. Di Marco, M. Lanza, M. Pieruccini, Dynamical mechanical measurements in dry PHEMA and its hydrogels, Nuovo Cim. 16 (1994) 849-854.

[47] A. Hensel, J. Dobbertin, J.E.K. Schawe, A. Boller, C. Schick, Temperature modulated calorimetry and dielectric spectroscopy in the glass transition region of polymers, J. Therm. Anal. 46 (1996) 935-954.

[48] S. Havriliak, S. Negami, A complex plane analysis of $\alpha$-dispersions in some polymer systems, J. Polym. Sci. Part C. 14 (1966) 99-117.

[49] S. Havriliak, S. Negami, A complex plane representation of dielectric and mechanical relaxation processes in some polymers, Polymer (Guildf). 8 (1967) $161-210$.

[50] P. Steeman, J. Van Turnhout, A numerical Kramers-Kronig transform for the calculation of dielectric relaxation losses free from Ohmic conduction losses, Colloid Polym. Sci. 275 (1997) 106-115.

[51] F. Kremer, A. Schönhals, Broadband Dielectric Spectroscopy, Sp, Berlin, 2003.

[52] T.R. Hesketh, J.W.C.V.A.N. Bogart, S.L. Cooper, Differential scanning calorimetry analysis of morphological changes in segmented elastomers, Polym. Eng. Sci. 20 (1980) 190-197.

[53] D.L. Sidebottom, B. Roling, K. Funke, Ionic conduction in solids: comparing conductivity and modulus representations with regard to scaling properties, Phys. Rev. B 63 (2000) 024301.

[54] J.C. Dyre, The random free energy barrier model for ac conduction in disordered solids, J. Appl. Phys. 64 (1988) 2456-2468.

[55] A.K. Jonscher, Dielectric relaxation in solids, J. Phys. D. Appl. Phys. 32 (1999) 57-70.

[56] G. Hartwig, Polymer Properties at Room and Cryogenic Temperatures, Springer US, Boston, MA, 1994.

[57] S. Lustig, J. Caruthers, N. Peppas, Dynamic mechanical properties of polymer-fluid systems: characterization of poly (2-hydroxyethyl methacrylate) and poly (2hydroxyethyl methacrylate-co-methyl), Polymer (Guildf). 32 (1991) 3340-3353.

[58] M.C. Shen, J.D. Strong, Low-temperature internal-friction study of diluent effect in some polymethacrylates, J. Appl. Phys. 38 (1967) 4197-4202.

[59] K. Mohomed, F. Moussy, J.P. Harmon, Dielectric analyses of a series of poly(2hydroxyethyl methacrylate-co-2,3-dihydroxypropyl methacylate) copolymers, Polymer (Guildf). 47 (2006) 3856-3865.

[60] L.V. Karabanova, G. Boiteux, G. Seytre, I. Stevenson, O. Gain, C. Hakme, E.D. Lutsyk, A. Svyatyna, Semi-interpenetrating polymer networks based on polyurethane and poly(2-hydroxyethyl methacrylate): dielectric study of relaxation behavior, J. Non-Cryst. Solids 355 (2009) 1453-1460.

[61] R. Sabater I Serra, J.L. Escobar Ivirico, J.M. Meseguer Duenas, A. Andrio Balado, J.L. Gomez Ribelles, M. Salmeron Sanchez, Dielectric relaxation spectrum of poly ( $\varepsilon$-caprolactone) networks hydrophilized by copolymerization with 2-hydroxyethyl acrylate, Eur. Phys. J. E Soft Matter 22 (2007) 293-302.

[62] J. Kolarik, J. Janacek, Dynamic mechanical behavior of poly(2-hydroxyethyl methacrylate)-glass beads composites, J. Appl. Polym. Sci. 20 (1976) 841-851. 